\title{
LAS DOS ORILLAS: CECILIA Y FORTUNATA
}

\section{Novela y Sociedad}

"La sociedad presente como materia novelable", asi tituló Galdós su discurso de ingreso en la RAE y, ciertamente, si hay algo que vincule las novelas objeto de reflexión -Cecilia Valdés (1882) y Fortunata y Jacinta (1886) - es, precisamente, la constatación de este hecho.

Una clase en formación no vacila en los primeros momentos de progresión social hacia el poder, en valerse de todos los medios de expresión; surge así la novela, expresión enteramente original, como hecho social, como "escritura de la historia" y como instrumento de lucha ideológica.

Desde este punto de vista, podriamos definir tres momentos en la evolución de la novela decimonónica: momento revolucionario (de lucha por el poder), momento conservador y momento crítico.

La burguesía o "preburguesía" revolucionaria pronto se hace conservadora, para defender un sistema amenazado por nuevos peligros. La novela, en este momento, se apresura a mostrar los elementos siniestros absorbidos por la bondad del sistema (Cecilia Valdés). Ciertos autores dan un paso más, para ofrecer una visión crítica del propio sistema (Fortunata y Jacinta). Así, si Galdós crea una novela extraordinaria por la riqueza exuberante de sus caracteres, la flexibilidad de sus procedimientos narrativos, el control sutil del juego de ideas en conflicto (lucha por adaptarse o rechazar el medio) y el análisis que ofrece de la sociedad de la Restauración y de las relaciones de interdependencia de los miembros de las diferentes clases sociales, y ello, desde una perspectiva intensamente crítica, Cirilo Villaverde, más ecléctico y contradictorio, crea una obra que, si bien ideológicamente simple, ofrece un análisis profundo de la sociedad cerrada de un país periférico, en uno de los momentos más conflictivos de la etapa esclavista y colonial, la Cuba que va de 1812 a 1830: esclavitud, régimen colonial represivo, formación de la conciencia criolla...

Y esto es precisamente lo que las une, ambas son una "pintura" de la sociedad que "novelan". La sociedad habanera y cubana de principios del XIX, y la sociedad metropolitana de la Restauración muestran sus taras en un doble plano -el individual y el colectivo-, taras que explican y, a la vez, desencadenan un proceso de crisis a ambos lados del Atlántico que, finalmente, culminará con los acontecimientos del 98 , que abrirán nuevas vías en la búsqueda de identidad de ambos pueblos.

Pero si la novela galdosiana muestra las taras desde una perspectiva crítica -situándonos en los parámetros mencionados-, Cecilia Valdés participa tanto del momento revolucionario (crítica contumaz de lo español y lo que representa: colonialismo, militarismo, represión contra el "criollismo"...), como del conservador: la esclavitud es tolerable en determinadas circunstancias, que son las que se reclaman.

En definitiva, ambas constituyen sendos calidoscopios sociales, aunque varía el enfoque. 
Algunos autores mantienen que América Latina carece estrictamente de novela en el s. XIX, $\mathrm{y}$ que es en el s. XX cuando se establece una forma literaria ajustada a la cosmovisión de los sectores medios emergentes, sin embargo la novela de Cirilo Villaverde desmiente esta teoria.

\section{Singularidad de la orilla americana}

Las tendencias literarias europeas llegaron a la América decimonónica, no obstante, adoptaron allá su propia lógica:

En relación con las dificultades que se manifiestan en las naciones independientes salidas de la guerra, triunfa en Hispanoamérica el Romanticismo: búsqueda de identidad, derecho del hombre a ser libre..., triunfo que algunos autores sitúan entre 1840 y 1890 , y que se vincula, de algún modo, a la función, que se autoasigna una elite contradictoria, de formación de una América nueva.

Mientras, Cuba y Puerto Rico, todavia sometidas a dominio español, muestran una creciente intranquilidad, que se manifiesta en una literatura impetuosa y combativa. Su situación, atípica en el contexto, hace que el Romanticismo americano adquiera en Cuba un tono especial.

No olvidemos tampoco que la colonización de América del Sur fue una colonización de extracción, no de asentamiento, lo que hace que Cuba, pese a la dependencia politica de España, dependa comercialmente cada vez más de Estados Unidos, a los que liega a vender el $80 \%$ de su producción azucarera, así que los intereses comerciales refuerzan la unión contra España, para renovar los aranceles y beneficiarse de los privilegios del gran vecino del norte. En estas circunstancias, las fuerzas políticas, capitaneadas por la burguesía criolla independentista, se enfrentan a los españoles dentro y fuera de la isla.

Este sentimiento anti-español podemos situarlo en un marco más amplio que, sin duda, también refleja Cecilia Valdés:

- A partir de los movimientos independentistas, se crea una visión de España asociada a los tiempos de tiranía y barbarie de Fernando VII, que no se romperá hasta el 98. Lo español es lo rechazable, la incapacidad para la modernización de la cultura.

- La idea paralela de que hay un terreno hostil de población no preparada, que hay que educar. Dicho de otro modo: hay una población bárbara de africanos e indios, más una rémora tradicional, que es la cultura española. América debe encontrar el camino de la civilización.

Desde este punto de vista, tanto el clero conservador, cuyos intereses chocan contra los de los movimientos liberales que llegan al poder, como España -país con taras-, constituyen una rémora para el progreso (sentimiento anti-español y anti-clerical) pero, paralelamente, el malestar profundo provocado por la desconfianza en el proceso general de modernización, produce una sensibilidad nostálgica (a veces relacionada con la propia biografia del autor), que se manifiesta en un Romanticismo añorante de tipo conservador. El vértigo que la modernización impone exige aferrarse a algo estable, los más pesimistas piensan que el mestizaje hace imposible el progreso (idea reforzada por el positivismo); otros, como José Martí, creen que hay una dimensión profunda de armonía donde no hay razas, y que para que América camine, es necesario que caminen el indio y el negro; otros, finalmente, no 
escapan de su propio maremágnum de ideas contradictorias, que reflejan en sus obras. Este es el caso, a mi juicio, del autor de Cecilia Valdés: antiespañolismo, anticlericalismo, racismo, sensibilidad nostálgica y, a la vez, mestizaje como mito y símbolo de simbiosis cultural. En definitiva, ideas contradictorias de una clase social amenazada por la devaluación de la mano de obra esclava, frente a los avances técnicos foráneos.

Sacarocracia, cuyos intelectuales, conscientes de la crisis, utilizan la literatura para conseguir sus aspiraciones reformistas contra la España colonial, esto es, corregir los excesos pero sin tocar los intereses de la naciente burguesia criolla frente a las autoridades de la Corona. De modo que escamotean la rebeldia abierta y optan por un "principio estético" acorde a su ideología conservadora, con el propósito de corregir ciertos errores en beneficio de su clase: no abolición de la esclavitud, sino supresión de la trata, ya que la importación ilegal amenazaba con acrecentar la población negra sin las ventajas antes disfrutadas. Sin duda, los problemas económicos, más los conflictos sociales y políticos, constituian una "bomba" para los intereses de los azucareros.

En este contexto, Cirilo Villaverde pertenece al grupo de creadores jóvenes agrupados en torno a Del Monte -citado en su obra junto a J. A. Echevarria-, reformistas, no revolucionarios, que usan la pluma en favor de sus ideas (incoherencia y dispersión crítica) y tratan el tema de la esclavitud, orientado hacia el costumbrismo literario y el eclecticismo, pretendiendo reformar la sociedad para gozar de las libertades de otros países continentales.

El programa social que vienen a exponer estos intelectuales es el que sigue: apoyo a intereses económicos criollos, más preocupación por crecimiento desproporcionado de negros en la isla, más preferencia por la reforma sobre la revolución.

Sin embargo, aunque la crítica que Cirilo Villaverde hace de la esclavitud no atenúa sus ideas peyorativas sobre los negros -únicamente Martí, entre sus coetáneos, está libre de este prejuicio-, nos ofrece una realidad: el"sincretismo social", que toma el "blanqueo" como norte y guía en el progreso social, que permite a negros y mulatos una cierta movilidad.

Cirilo Villaverde, narrador cubano del período romántico, de obra netamente americana por temas e intenciones, pese a entroncar con el Costumbrismo y utilizar elementos del Romanticismo sentimental, se precia de ser realista. Así lo manifiesta en el prólogo a la edición de 1882: "Me precio de ser, antes que otra cosa, escritor realista, tomando esta palabra en el sentido artístico que se le da modernamente (...) Retrato de (...) personajes vivientes, descripción de costumbres y pasiones de un pueblo de carne y hueso, sometido a especiales leyes políticas y civiles, imbuido en cierto orden de ideas y rodeado de influencias reales".

\section{Proceso de creación de la novela}

El prolongado proceso de elaboración de Cecilia Valdés (más de 40 años), sometido, además, a numerosas interrupciones, es un factor que podria explicar ciertos desajustes estructurales, así como la incidencia de diversas tendencias literarias (románticas, costumbristas, realistas, "pseudonaturalistas"...), no olvidemos que en los años finiseculares -1882-, el mestizaje de estilos, sobre todo en América, era una realidad relevante.

Las versiones primitivas (1839) mantienen una orientación "neutra", quizá obligada -como señala A. Schulman en su prólogo a la novela ${ }^{1}$ - por las condiciones de censura a que 
estaban sometidas las artes, condiciones que explicarían observaciones de autor como la que sigue: "La sociedad en general casi nunca es injusta en sus fallos".

La versión definitiva, publicada en 1882 en Nueva York, mantiene las abundantes y pormenorizadas descripciones de lugares y personas, propias del relato costumbrista, pero su situación de exilado, fuera del marco sociopolítico y cultural de la vida colonial, le permite una mayor claridad de planteamientos, que si bien llegan a ser radicales contra el poder español en la isla, no pueden considerarse, en ningún modo, un alegato contra la esclavitud.

La fecha de 1882 suma al alejamiento geográfico aludido, el distanciamiento temporal sobre los hechos que relata. Sin duda, la conciencia de Villaverde despierta al hilo de los acontecimientos históricos y sociales en tan dilatado período de tiempo (guerras, triunfo del liberalismo, conciencia obrera de la población que se opone a la explotación, conatos rebeldes, pactos...), acontecimientos que precipitan a Cuba y España a una crisis total. Esto amplia la perspectiva socio-cultural y enriquece la obra; la cual, por otra parte, supera los estrechos límites del proyecto sentimental de la edición de 1839 , para convertirse en una "pintura" singular de la sociedad cubana de la época: amalgama de normas morales, capas económicas y sociales, transferencias culturales, tradiciones, costumbres... Sociedad sometida a metamorfosis, reflejo de una economía cuyos medios de producción se van transformando a medida que se absorben los adelantos técnicos. Y es en esto, precisamente, donde radica la singularidad de la obra, posible gracias a la privilegiada situación de observador a distancia de su autor, que le permite descubrirnos un mundo cerrado, sin apenas conciencia, desde dentro, de sus enormes limitaciones.

La fecha de publicación de la versión definitiva -1882 - y su "giro" reaiista y social la aproximan a Fortunata y Jacinta -1886-, obra con la que mantiene curiosas coincidencias.

\section{Elementos compartidos}

Ambas utilizan la estructura de folletín, sombra folletinesca que, por otro lado, se percibe en la mejor novela realista decimonónica.

El triángulo Leonardo-Isabel-Cecilia es paralelo al de Juanito-Jacinta-Fortunata, simbolizando cada individuo un determinado grupo social. Destaca el protagonismo del pueblo (Fortunata-Cecilia), engañado por un miembro de la clase dominante (Juanito-Leonardo), así como el fruto de ese engaño: el hijo o hija, que si bien es asimilado por el poder en Fortunata y Jacinta, es abandonado a su suerte en Cecilia, donde las posibilidades de movilidad social, aunque presentes, son más remotas, y directamente proporcionales a la pretensión de ascenso, más evidente en Cecilia, porque su belleza "no constituía título abonado para salir ella de la esfera en que había nacido y elevarse a aquella en que giraban los blancos de un país de esclavos" (1a parte Cap.X). No obstante, Cecilia y Fortunata creen, de algún modo, mejorar a través del hijo, hijo que podría representar, asimismo, el mestizaje, la mezcla de clases sociales, vaga esperanza en el fin de la injusticia y la desigualdad.

Las características de Leonardo-Juanito, atribuibles a la clase que representan, coinciden sorprendentemente; ambos viven sin trabajar, al amparo de sus respectivas madres ( $D^{a}$ Rosa y Barbarita):

1 Villaverde, Cirilo: Cecilia Valdés o la Loma del Angel. Caracas: Biblioteca Ayacucho, 1981. 
Dice Leonardo (pudiera decirlo Juanito): "Me peno por una muchacha mientras me dice que no; en cuanto me dice que sí (...), se me caen a los pies las alas del corazón" o "Para gozar mucho en la vida el hombre no debe casarse con la mujer que adora, sino con la mujer que quiere" (3a parte Cap.I) Paralelamente, leemos en Fortunata y Jacinta: "Lo que tienen desprecian, y lo que ven guardado (...) es lo que se les antoja". (2a parte Cap.VII)

Ambos representan la generación heredera de la clase dominante: apática, inmadura y viciada por las lacras sociales -además ruda y brutal en el caso de Leonardo-. No tienen que preocuparse por su futuro, viven únicamente ocupados de sus calaveradas, ni siquiera toman en serio sus estudios de Derecho. El grupo de estudiantes que acompaña a Leonardo -Gamboa, Meneses y Solfa- es semejante al que acompaña a Juanito -Villalonga...-, incluso se divierten con lo mismo (el pueblo); los unos dirigiéndose a la Loma del Ángel; los otros, a los barrios de Madrid.

Frente a ellos, Cecilia y Fortunata representan la belleza de ese pueblo que "conserva las ideas y los sentimientos en su tosca plenitud", en palabras de Galdós, lo esencial de la humanidad, lo auténtico, lo primitivo, los grandes sentimientos. Así se manifiesta Cecilia (pudieran ser palabras de Fortunata): "A V. no le interesa mi amistad, se conoce, y soy una boba que le espero. (Maldita sea la mujer que quiere como yo!". (1a parte Cap. X) Ambas representan el ímpetu de lo natural frente al control social que representa la relación con JacintaIsabel, el amor como fuerza incontrolable que puede poner en peligro la estabilidad social. Aman por un sentimiento espontáneo de su ardiente naturaleza: si Cecilia "Nunca había oído decir que era pecado no querer a quien no le gusta a uno"(2a parte Cap. IV), paralelamente, Fortunata se pregunta "¿Pero qué culpa tengo yo de no querer a mi marido?”. (3a parte Cap. VI.10)

En ambos casos, para "calzar al pollo" que se está "desmandando", los papás proponen casamiento. El tercer vértice del triángulo (Jacinta-Isabel) es el contrapunto de su clase, su calidad moral -mayor conciencia de la injusticia social- eleva a Jacinta e Isabel sobre sus compañeros varones, representando la esperanza en la reforma que evitaría la revolución del pueblo explotado y oprimido (Dionisio el negro). Sin embargo, existe una diferencia fundamental entre ellas: Isabel encarna lo conservador, la nostalgia por un pasado idealizado (relación de servidumbre amo-esclavo donde todos son felices), mientras que Jacinta representa la actitud critica frente a los de su propia clase (finalmente, abandona a Juanito).

Las coincidencias estructurales y folletinescas se suceden: si Galdós, tras presentarnos a la familia de Juanito Santa Cruz y la enredadera oligárquica, se detiene en el entorno familiar difuso de Fortunata (parientes y amigos), estableciendo nexos entre ambas ( $\mathrm{D}^{\mathrm{a}}$ Lupe la de los pavos, etc.), Villaverde nos presenta un entorno familiar muy estructurado, el de Leonardo, y frente a él, el entorno poco definido de Cecilia (Señá Josefa, Nemesia, José Dolores Pimienta, el sastre Uribe y Señá Clara), estableciendo entre ellas, vínculos paralelos (los esclavos Maria de Regla y Dionisio, la sastrería Uribe). Las interrelaciones entre ambas familias, de contextos sociales dispares, y la dialéctica de poder que se establece entre ellas y en el seno de cada una, da lugar a un panorama tipológico y social de enorme riqueza que evidencia las enormes contradicciones y desequilibrios de la sociedad que cada novela presenta. 
Al hilo de los episodios folletinescos, reparemos en una nueva coincidencia: FortunataCecilia (pueblo engañado) proponen a sus respectivos enamorados (Maxi-Pimienta) que maten al culpable de su situación (Juanito-Leonardo); finalmente, sólo Pimienta lo consigue.

Volviendo a la idea ya mencionada de novela como "escritura de la historia" que ambos comparten, si la presencia de los acontecimientos históricos contemporáneos es obvia en Fortunata y Jacinta, lo es también en Cecilia Valdés, donde las referencias históricas son permanentes, hilvanando una feroz critica de la política colonial (falta de libertad, prohibición de discusión política...) que "Se basaba en el principio maquiavélico de corromper para dominar" (la parte Cap. IV), paralela a la que Galdós hace de la Restauración. Veamos algunas de estas referencias en Cecilia Valdés:

“Algunos años adelante (...) después de la caída del segundo breve periodo constitucional, en que quedó establecido el estado de sitio..."(1 ${ }^{\mathrm{a}}$ parte Cap. I)

"El derecho de reunión no se practicaba en Cuba desde 1824, en que se acabó el segundo periodo del sistema constitucional"(2a parte Cap. VII)

"Vargas y Dodge (...) barbero el uno, carpintero el otro, que fueron comprendidos en la supuesta conspiración de la gente de color de 1844 y fusilados"(2a parte Cap. XVII)

"Mientras aquella loca juventud gozaba a sus anchas de los placeres del momento, el más estúpido y brutal de los reyes de España parecía contemplarla con aire de profundo desprecio desde el dorado dosel donde se veía pintada su imagen odiosa"( ${ }^{\mathrm{a}}$ parte Cap. III)

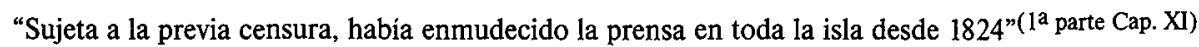

"Vivian en la ignorancia del derecho del hombre libre bajo el despotismo metropolitano"( ${ }^{\mathrm{a}}$ parte Cap. XI)

"De la del año 12 sólo sobrevivía el nombre de Aponte (...) porque siempre que se ofrecia pintar a un individuo perverso, exclamaban la viejas: (Más malo que Aponte!"(1a parte Cap. XI)

"En aquellos tiempos en que la Metrópoli creia que la ciencia de gobernar las colonias se encerraba en plantar unos cuantos cañones de bateria, se ideó la construcción de las murallas de La Habana, obra que se comenzó a principios del décimo séptimo del siglo y se terminó al finalizar el décimo octavo"(2a parte Cap. II)

Leonardo, representante de la nueva generación cubana:

“Alcanzaba nociones muy superficiales sobre la situación de su patria en el mundo de las ideas y de los principios (...) no se cuidaba de la política y por más que le ocurriese alguna vez que Cuba gemia esclava, no le pasaba por la mente siquiera entonces, que él o algún otro cubano debía poner los medios para libertarla" (1 ${ }^{\text {a }}$ parte Cap. XI)

Otro aspecto compartido es el anticlericalismo, nota permanente en la novela de Villaverde, que presenta ceremonias religiosas más grotescas que devotas, y culmina irónicamente con estas palabras de un cura racista: "mi opinión es que no debe esperarse de gente tan ignorante, como los negros, el que juzguen y actúen cual las criaturas racionales". ( ${ }^{\mathrm{a}}$ parte Cap. IV)

La idea del enriquecimiento de muchos a costa de desvalijar Cuba y Filipinas está presente en ambas: "Dicen que América para los americanos ¡vaya una tontería! América para los usureros de Madrid". (Fortunata y Jacinta 2a parte Cap. III .5)

La descripción que Villaverde hace de los comercios de La Habana ${ }^{\left(2^{\mathrm{a}} \text { parte Cap. 1) }\right.}$ recuerda vagamente la que hace Galdós de los comercios de Madrid. 


\section{Otros aspectos compartidos son:}

El uso de diferentes registros lingüísticos en función del estrato social del personaje, así como el gusto por el lenguaje popular y los refranes: "Piensa mal y acertarás". (Cecilia Valdés 2a parte Cap. X)

La instrucción como elemento de dignificación social y relativa movilidad, ésta permite a los negros ser protagonistas: el capitán de color cuya instrucción le dota de ascendiente mágico entre los de su raza -siempre el elemento ideológico contradictorio atenúa el planteamiento-; el contramayoral que, a pesar de no saber cuentas, leer ni escribir, es capaz de desarrollar el trabajo gracias a su inteligencia (en este caso, la critica va implícita). ${ }^{\left(3^{a} \text { parte Cap. I) }\right.}$

La referencias literarias son otro elemento presente en ambas obras. Uno de los coetáneos aludidos por Villaverde es Domingo del Monte "Que introdujo el romance cubano, de variados conocimientos y muy distinguido porte”. (2a parte Cap. III)

Igualmente, podemos apreciar cierto paralelismo entre la visita que realiza Jacinta a los talleres, en su viaje de novios de Barcelona a Valencia, y su actitud ante la explotación: "Vale más ser mujer mala que máquina buena"( (1a parte Cap. V.3), y la que realiza Isabel a los ingenios, donde contempla el trabajo de los negros, ambos episodios remiten a la entrada del progreso (máquinas de vapor, etc.) y lo que ello conlleva, aunque, ciertamente, es más evidente la actitud crítica en Jacinta.

\section{Lo distintivo en Cecilia Valdés}

Si bien, ambos autores comparten ciertos referentes que sus obras reflejan, no es menos cierto que la orilla americana, concretamente cubana, tiene los suyos propios, que se manifiestan en la obra de modo singular:

Villaverde capta la dinámica de la sociedad cubana en términos de antítesis, manejando así las tensiones de las clases emergentes y las divisiones sociales, raciales y económicas motivo de pugna étnica y nacional:

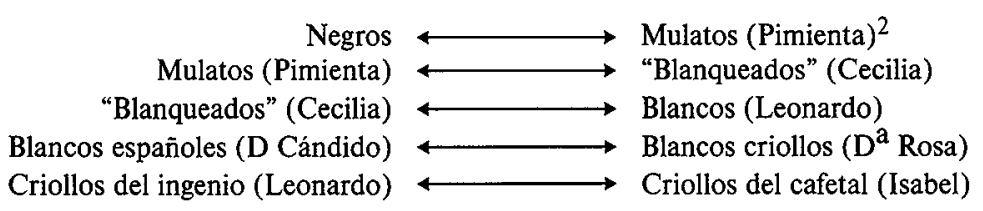

El desarrollo de tales antitesis facilita una cierta progresión social mediante el procedimiento de "blanqueo", que permite al hombre mestizo "Ser tolerado en la sociedad del hombre blanco. Pero del mismo modo que éste maltrata brutalmente al negro esclavo, el gobernante español maltrata al criollo, de manera que el autor nos introduce en un juego de asociaciones que nos lleva a identificar al déspota gobernante español con el cruel amo del ingenio: éste maltrata a su esclavo negro, como aquel a la incipiente nación cubana. Las imágenes se suceden insistiendo en ello. Desde este punto de vista, se puede apreciar un conato de revolución, que el autor se apresta a sofocar: hay criollos esclavistas "buenos" -Isabel Ilincheta y sus tíos- que tratan bien

2 Simbolizada en la pelea a muerte entre Pimienta (futuro inmediato) y Dionisio el negro (inquietud más a largo plazo). 
a "sus" esclavos, lo que no hay son gobernantes españoles "buenos" que traten bien a "sus" cubanos, y es aquí donde se manifiesta la ideología del criollo separatista con meridiana claridad.

Finalmente, la convivencia "humanitaria" del negro -elemento ínfimo de la escala- subordinado al blanco criollo del cafetal, que Isabel representa -elemento superior-, satisface los anhelos reformistas, que no revolucionarios, del autor, el cual usa el argumento anti-esclavista en tanto en cuanto le sirve como mecanismo que aguza la aversión a lo español, con el juego de paralelismos que a tal fin establece, pero no va más allá. El argumento anti-esclavista no es más que un pretexto que pretende favorezca sus intereses de clase.

Asimismo, Cecilia Valdés presenta un patrón determinista ausente en Fortunata y Jacinta: "La misma expresión fisonómica, el mismo espiritu llevaba impreso en el rostro el sello de su progenie". (1a parte Cap. Xl) Leonardo parece condenado a perpetuar los defectos de su padre, como Cecilia a seguir los pasos de su madre, incluso su abuela se pregunta: “Sería posible que la nieta siguiera el mismo camino y casi por los mismos medios se perdiera como su desventurada madre?' (4a parte Cap. II) Hay autores que interpretan este determinismo como mecanismo para señalar la decadencia irremediable de Cuba sin la abolición de la esclavitud (que no se produjo definitivamente hasta 1886 ); en este mismo sentido, interpretan la profusión de crimenes, incestos... en la obra de los escritores de la generación de Villaverde; pesadillas que también pueblan esta obra, individuos que sufren la tragedia de la represión de la sociedad colonial de Cuba. Otra lectura es que el autor, víctima de sus propias contradicciones, no es capaz de romper este patrón determinista, ruptura que supondría un amago revolucionario no acorde con sus planteamientos.

El sentimiento anti-español está presente en toda la obra. Alusiones intensamente despectivas, en todos los sentidos, se suceden (sentimiento que debe interpretarse en el marco contextual del s. XIX americano, ya aludido):

Alusión a mezcla de razas en la península: "Ya. No eres esclavo, pero alguno de tus progenitores lo fue sin duda y tanto vale". (1a parte Cap. VIII)

Dureza de las leyes españolas: "Es bien sabido que la justicia española lleva su saña hasta las puertas del sepulcro". (1 ${ }^{\text {a }}$ parte Cap. VIII)

Cobardía: "Para subsanar su conducta cobarde, se ocuparon de falsear sucesos, califi-

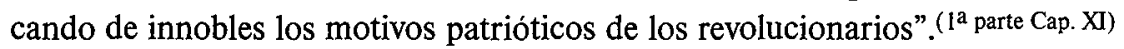

Ironía sobre el "estudiante españolado", que se mantiene en comentarios como "Estos mozos españoles son a veces demasiado impertinentes" (situando el problema separatista muy por encima del social), o episodios como el del carruaje y el caballo cargado de forraje o como el del Paseo del Prado, que muestran el abuso de poder de los militares españoles.

Don Cándido, seco, taciturno, duro y tacaño, "hombre ignorante y rudo"( $1^{\text {a }}$ parte Cap. XI) representa el elemento español que engaña a lo criollo (la esposa) y a lo mestizo (Charo), y se enriquece con la trata legal e ilegal de los esclavos, a quienes trata brutalmente. Leonardo, hijo de español y criolla, falso, sinvergüenza, soberbio y orgulloso -"Ten presente que Isabel es hija de un antiguo empleado del gobierno, empleado cesante (...) un pobretón, en suma; mientras que mis padres tienen potreros, cafetal, ingenio, son hacendados ricos y hacen diferente papel en La Habana ¿Está V.?”( $3^{a}$ parte Cap. II)_, representante de la nueva generación, odia a su padre: "Figúrate, mamá, -dijo Leonardo con mucha risa, aunque bajando 
la voz- un plagiario de hombres convertido en conde... del Barracón, por ejemplo. ¡Qué lindo título! ¿No te parece mamá?”. (1a parte Cap. XII)

A pesar de ello, hereda sus actitudes: engaña a Cecilia, apalea brutalmente a Aponte, maltrata permanentemente a los esclavos... También hereda su rudeza: "introduciéndose los dedos en la boca arrojó cuanto había comido".(1 parte Cap. VI)

Sin embargo, y he aqui una de las incoherencias no resueltas del autor: "La aspereza suya no era sino externa, estaba en sus maneras bruscas, porque allá en el fondo de su pecho, como habrá ocasión de observarlo, había raudal inagotable de generosidad, ternura de sentimientos". Ciertamente, la trama no confirma esta observación, sí la vaga esperanza del autor en el futuro que Leonardo representa.

El odio que Leonardo siente por su padre es, en parte, recíproco: "Lo desnuco (...) como me llamo Cándido, y hago que le den chicote a ver si suelta alguna de la sangre criolla que tiene en las venas". $\left(^{\mathrm{a}}\right.$ parte Cap. $\left.\mathrm{X}\right)$

Junto al futuro criollo que Leonardo representa, su madre, Da Rosa, es la criolla débil que, aunque poderosa, no sólo consiente la conducta del español, sino que la justifica, cuando no, la aplaude: "Da Rosa, mujer cristiana y amable con sus iguales, que se confesaba a menudo (...) sentimos decirlo, al ver las contosiones de aquellos a quienes la punta del látigo de cuero trenzado del mayoral habría surcos (...) se sonreía" (3a parte Cap. V), eso sí, el autor reconoce que "siente decirlo".

Otros comentarios refuerzan la aversión por lo español: "Espectáculo bárbaro como el de las corridas de toros" ${ }^{2}$ parte Cap. VII $)$, sentimiento que enlaza con la crítica de la política colonial (desorden administrativo, penuria del erario, corrupción de jueces y empleados, atraso general, ignorancia, ausencia de moral...). Al hilo de esta crítica, se suceden los comentarios alusivos a los españoles que van a Cuba a enriquecerse, no a trabajar, hijos de un pueblo que desprecia el trabajo, desprecio que trasladan a Cuba: "País insoluble donde el trabajo recio e incesante se imponía como un castigo y no como un deber del hombre en sociedad" (3a parte Cap. III), por lo que "Vendrán a menos los bienes cada día".(3a parte Cap. VII)

La aversión hacia lo foráneo, no se reduce a lo español. A Villaverde, sagaz observador, no se le escapa el peligro anglosajón: "Esos ingleses protestantes se figuran que el mundo entero les pertenece" $\left(2^{\mathrm{a}}\right.$ parte Cap. $\left.\mathrm{V}\right)$. Sentimiento que reaparece en el Cap. VI al referir el apresamiento de "Veloz".

Otro elemento presente en la obra es un prejuicio racial no superado (estimulado por las doctrinas positivistas, supuestamente cientificas, que triunfaron a partir de los años 60), que muestran comentarios como el que apostilla una de las descripciones de Cecilia: "No dejando el ánimo vagar sino para admirarla, y pasar de largo por las sobras o faltas de su progenie" ${ }^{\text {a }}$ parte Cap. II), o este otro referido a Pimienta: "Era de la raza híbrida o inferior" (12 parte Cap. VI), o el que sigue, alusivo a los esclavos de Isabel: "Los recibió con los escorrozos tan propios de las gentes de su raza y condición". (3a parte Cap. I)

Junto al componente anterior, a veces asoma una tímida crítica, no exenta de ironía, como en el episodio de la blanca condenada a muerte: "Sólo a la blanca se le hace morir en garrote noble". (1 ${ }^{\mathrm{a}}$ parte Cap. IX) 
La idea de la degradación moral del blanco en contacto con la esclavitud, que embrutece a quien la ejerce, $y$, paralelamente, la degradación de una sociedad esclavizada (cruce de planos y dobles sentidos con que el autor juega intencionadamente), es recurrente: esclavitud "Que debilita el sentimiento de la propia dignidad (...) en el código no escrito de los amos de esclavos no se conoce proporción ni medida entre los delitos y las penas" (2a parte Cap. IX), "Veneno en el alma de los amos (...) como si tratado como bestia se extrañara que se portara a veces como fiera" (3a parte Cap. VI), "Música tan plañidera como voluptuosa, pues que procede del corazón de un pueblo esclavizado"( $2^{\mathrm{a}}$ parte Cap. III), "Imposible que lo entiendan en toda su fuerza aquellos que no han vivido jamás en un país de esclavos"( $2^{\mathrm{a}}$ parte Cap. V), "Porque es condición de esclavo no acertar nunca a complacer a sus amos". (2a parte Cap. V)

$\mathrm{Y}$ junto a estos comentarios, son varios los episodios que muestran una realidad brutal, como el del penoso viaje del barco negrero desde África.

Cúmulo de ideas ambivalentes y contradictorias, donde el límite racismo-critica de la esclavitud es, a veces, confuso, que culmina en la sorprendente imagen: "Somos un alma negra". ${ }^{3 a}$ parte Cap. VI)

Sin embargo, aunque confuso y contradictorio, Villaverde no niega al esclavo que tiene alma y piensa: "Pero si aquella era su suerte y no habia remedio ¿a qué apurarse ni afligirse anticipadamente? Así reflexionaba él, y así poco más o menos, todos sus compañeros, a quienes Dios, en su santa merced, no había negado un alma pensante" ${ }^{\mathrm{a}}$ parte Cap. $\left.\mathrm{V}\right)$. Igualmente, tras el desprecio e indiferencia que muestra $\mathrm{D}$. Cándido ante la brutalidad con que es tratada la "Mercancía procedente de África" - "Fueron al mar los fardos que habia sobre cubierta..." $\left(22^{a}\right.$ parte Cap. VI)_: "Tú te has figurado que los sacos de carbón sienten y padecen como nosotros (...) $\mathrm{Y}$ dale con creer que los fardos de África tienen alma (...) cuando el mundo se persuada que los negros son animales y no hombres..." (2a parte Cap. VI), el autor interviene para añadir: "Carga compuesta de seres humanos, diga él lo que quiera". (2a parte Cap. VI)

Su preocupación por la situación del pueblo no va más allá de algún "desliz", como aquel en que la "Señá Chepa" señala su alienación, su no existencia a D. Cándido: "Acuérdese lo que semos: nada"(1a parte Cap. I). Por el contrario, frente al pueblo fuerte y auténtico de Galdós que "Conserva las ideas y los sentimientos elementales en su tosca plenitud (...) El pueblo que posee las verdades grandes y en bloque, donde acude la civilización conforme se le van agotando las menudas de que vive"(Fortunata y Jacinta $3^{\text {a }}$ parte Cap. VII.3), el pueblo degradado y soez de Villaverde que "Se nutrió desde temprano con escenas de impudicia" (Cecilia Valdés $1^{\text {a }}$ parte Cap. II), un pueblo rudo, sensual y desmoralizado cuyos "Rasgos de galantería o de cariño en ninguna circunstancia tenían nada de delicados ni de finos"(Cecilia Valdés $1^{\mathrm{a}}$ parte Cap. $\left.\mathrm{VI}\right)-$ conflicto civilización/barbarie interpretado en términos antitéticos-, un pueblo que tiene asumida su inferioridad: "Era natural que creyera de bajos sentimientos a quien consentía en rozarse tan de cerca con la gente de color" (Cecilia Valdés $2^{\mathrm{a}}$ parte Cap. XVII). Planteamiento que confunde naturaleza y sociedad, confusión que los personajes de la obra galdosiana no comparten: "La que no pueda o no sepa dar a la Naturaleza lo que es de la Naturaleza y a la Historia lo que es de la Historia que se calle"(Fortunata y Jacinta $3 \mathrm{a}$ parte Cap. 1.6). Un pueblo inferior, que olvida su origen al ascender en la escala social: "Esperaba Cecilia ascender siempre, salir de la humilde esfera en que había nacido, si no ella sus hijos. Casada con un mulato, descendería en su propia 
estimación y en la de sus iguales: porque tales son las aberraciones de toda sociedad constituida como la cubana". (1a parte Cap. X)

Otro ejemplo encontramos en el "blanqueado" Sr. Uribe, que se jacta de su linaje racial, así como en Tirso, mulato que reniega de su raza.

Por otra parte, Cecilia quiere medrar, no Fortunata: “ $\mathrm{Si}$ es lo que a mí me gusta, ser obrera, mujer de un trabajador honradote que me quiera!"(3a parte Cap. V.5); y aunque ninguna de ellas tiene conciencia de clase, ni se hace reflexiones como ésta, de autor: "El oro purifica la sangre más turbia y cubre los mayores defectos, así físicos como morales"(Cecilia Valdés 3a parte Cap.X), Fortunata alcanza a sentir cierta rebeldia social: "Porque ella sería yo si estuviera en mi lugar (...) Porque si yo estuviera donde tú estás, sería... (Mejor que tú, mejor que tú!"(3a parte Cap. V.5), incluso "Llegó a creer que encenagándose mucho se vengaba de los que la habían perdido"(2a parte Cap. II.2). Rebeldía que es sustituida por afán de medro en Cecilia, y por resignación y paciencia en otros que, como el Sr. Uribe, confían en un proceso inevitable de transformación social y política -que en cierto modo, nos recuerda planteamientos krausistas-: "Los blancos vinieron primero y se comen las mejores tajadas; nosotros, los de color, venimos después y gracias que roemos los huesos. Deja correr, chinito, que alguna vez nos ha de tocar a nosotros. Esto no puede durar siempre asi"(2a parte Cap.I). Uribe a Pimienta le da un "curso de filosofia práctica" semejante al que Feijoo da a Fortunata, si éste se propone enseñarla a vivir: "Es nuestra obligación en este valle de lágrimas"( $3^{3}$ parte Cap. IV.1), aquel le aconseja: "Dejar correr y aprenderás a vivir". ${ }^{\text {a }}$ parte Cap. I)

Uribe y Pimienta representan una cierta rebeldía y esperanza en el futuro. Pero hay que aguardar ocasión: "Cuando son muchos contra uno, no hay remedio sino hacer que no se ve, ni se oye, ni se entiende, y aguantar hasta que le llegue a uno su turno. Que ya llegará, yo te lo aseguro". (2a parte Cap. I) Parece haber una esperanza para el pueblo, pero a largo plazo: lo mestizo, la sintesis.

El capítulo que describe el ambiente en el Paseo del Prado, se abre con unos versos aclaratorios:

No es caballero el que nace, sino el que lo sabe ser.

Está claro que la burguesía incipiente sí distinguía lo natural de lo social, sus intereses reclamaban mantener al pueblo en la ignorancia, pueblo del que también formaban parte los esclavos; sin duda, los pequeños cambios sociales que propone la novela evitarían el verdadero cambio, la verdadera revolución, que representa el negro Dionisio, o el negro Pedro cuando "Cansao de trabajar pa su amo", se rebela y declara que "El hombre no muere más que una vez". (3a parte Cap. V)

Y, al tiempo que Villaverde elabora su particular ensalada social, llevándose, políticamente, "el ascua a su sardina" (compromiso político que para muchos críticos es una tendencia de la literatura cubana), la sazona con singular preocupación por la forma y el estilo, así como con profusión de minuciosas descripciones: contradanzas y minués de corte, casa habanera, Colegio de San Marcos, Iglesia de Santo Ángel Custodio, modas, vestidos y peinados en el baile de la Sociedad Filarmónica, uniformes militares, casa del cafetal, paisajes con su amplia va- 
riedad de árboles...Aderezo costumbrista-esteticista que, en muchos casos, muestra el mestizaje cultural y la simbiosis social cubana.

\section{Una interpretación de la novela}

La trama folletinesca sobre la que se desarrolla la línea argumental -esfuerzo permanente de D. Cándido para distanciar a Leonardo de Cecilia- tiene una lectura alegórica: la unión de lo criollo (Leonardo) y lo mestizo (Cecilia) representa la hecatombe -incesto-, el fin del poder español en Cuba. El incesto se consuma, el fin del imperio español está próximo. El fruto de esa unión espera..., el futuro aguarda.

El tema esclavista, en este contexto ideológico, no es más que instrumento de refuerzo de su tesis, jugando continuamente con el doble sentido de la expresión "Cuba, país de esclavos". La actitud española: "Tú te has figurado que los sacos de carbón sienten y padecen como nosotros (...) Y dale con creer que los fardos de África tienen alma (...) cuando el mundo se persuada de que los negros son animales y no hombres..." (ya citada), y criolla, difieren: $\mathrm{D}^{\mathrm{a}}$ Rosa justifica la esclavitud con un planteamiento humanitario, ya que de este modo, se convierten en cristianos y en hombres, y ello en un escenario donde las bellezas del mundo físico contrastan con los horrores del mundo moral.

Y mientras ese hijo aguarda... Isabel representa la virtud y caridad cristianas (educada en las Ursulinas de La Habana), frente al norte triste y degradado de los ingenios de azúcar, donde "Cristalizan el jugo de la caña-miel con la sangre de millares de esclavos"( ${ }^{a}$ parte Cap. I), dominado por Leonardo - hijo, al fin y al cabo, de D. Cándido-, el autor opta por el alegre sur de los cafetales, donde amos y esclavos conviven felices, a pesar de ser víctimas "De la tiranía civil en su desventurada patria" ${ }^{3 a}$ parte Cap. V). Más allá de esa hija del incesto, algo más inquietante: la rebeldía del negro Dionisio y del negro Pedro, y la fuga de los negros "amarrones", cuya represión atroz e injusta, no hace más que aumentar su rebeldia.

Y cuando la brutalidad del amo llega a la cúspide: "Para ellos, que entendían por derecho únicamente aquello que no torcía el cumplimiento de sus pasiones y caprichos (...) Para el amo en general, el negro es un compuesto monstruoso de cinismo, de hipocresía, de bajeza y de maldad" (3a parte Cap. V), el elemento español se hace presente, en ese juego ideológico de ambivalencias que se suceden a lo largo de la obra: "Siempre se ha admirado más al inquisidor que más herejes mandaba al quemadero" (3a parte Cap. V), identificando al amo brutal con el inquisidor brutal, esto es, con el elemento español que la obra combate.

\section{DVA BREGOVA: CECILIA IN FORTUNATA}

$\mathrm{V}$ članku nam avtorica predstavi roman kubanskega pisatelja Cirilia Villaverde $\mathrm{z}$ naslovom Cecilia Valdés. Roman, ki je izšel leta 1882 v New Yorku, ima po besedah avtorice mnogo vsebinskih in formalnih podobnosti z romanom Fortunata y Jacinta španskega pisatelja Galdósa. Ko analizira stične točke in razlike med obema deloma, avtorica ugotavlja, da je najmočnejši element, ki ju druži, njuna vpetost v družbeno-politična dogajanja sedanjega časa, s čimer ta dogajanja postanejo glavni protagonist obeh romanov. 